\title{
National ICT Program- A Lever to Change Teachers' Work
}

\author{
Noga Magen-Nagar ${ }^{1, *}$, Tamar Shamir-Inbal ${ }^{2}$ \\ ${ }^{1}$ Education, Gordon College of Education, Haifa, Israel \\ ${ }^{2}$ Education and Psychology, Open University, Raanana, Israel \\ *Corresponding author: nogamagen@gmail.com
}

Received July 16, 2014; Revised August 11, 2014; Accepted August 17, 2014

\begin{abstract}
The current research examines the impact of the national ICT program on changing classroom performance of teachers in regard to both use of technology and perception of resulting changes. The research methodology integrated qualitative and quantitative methods. A total of 1,035 elementary school teachers who joined the program in 2010-2011 participated in a semi-enclosed questionnaire that was constructed especially for this research. The main finding indicates that a large-scale change occurred in teachers' classroom activity and in their perceptions of pedagogical essence, which is necessary for the integration of technology into teaching. However the findings indicate that most teachers use technology as a supplement for existing teaching-learning methods, and do not implement a meaningful change in their work that may lead to transforming the teachinglearning task from traditional to advanced digital teaching methods. It can be assumed that if the educational system continues to support the training of teachers and consistently and systematically outlines a suitable pedagogical path, a significant change in teachers' work characteristic of teachers can be expected in the course of the next several years.
\end{abstract}

Keywords: technological tools and services, digital teaching, digital learning, collaborative learning, pedagogical change

Cite This Article: Noga Magen-Nagar, and Tamar Shamir-Inbal, "National ICT Program- A Lever to Change Teachers' Work.” American Journal of Educational Research, vol. 2, no. 9 (2014): 727-734. doi: 10.12691/education2-9-4.

\section{Introduction}

Preparing educational system graduates for the 21st century is a need and major national goal in Israel. Since 2010 a national multi-year ICT program has been implemented under the title "Adapting the Educational System to the Needs of the 21st Century". The program encompasses hundreds of elementary and middle schools that constitute about $40 \%$ of Israeli educational institutions.

The program focuses on organizational and pedagogical aspects within schools and relies on support and resources from a national and local level. Goals of the program include: (1) laying the groundwork for a technology-rich environment; (2) training of internal teaching staff in schools, including principals and ICT coordinators in charge of the process within the schools; (3) preparing teacher teams to use and apply their digital teaching/learning integrated technology in the classroom; (4) promoting teaching and learning processes that implement personal and collaborative building of knowledge and independent inquiry-based learning combined with innovative technological tools; (5) creation of and accessibility to learning materials suitable for digital use; (6) using the LMS teaching system as an online organizational tool; (7) establishing a broad base of learning with home and class continuity, while expanding class and time-effective learning boundaries, and (8) responding to varied learners and diverse learning styles [16].

\section{Literature Review}

\subsection{Implementing Changes in the Educational System in Accordance Suitable to the Information Age}

In the technology age we live in, the implementation of teaching digital learning in schools is necessary in order to prepare graduates who will have the required skills for life in the information age. According to literature, it is expected that schools incorporating ICT over a period of time will experience significant changes in teaching methods and in the role of the teacher [14]. However the pressure on schools to present themselves as "innovative" often causes them to carry out actions that represent change, without having the change rationale become incorporated into the school's culture [8]. Teaching integration of digital learning in schools is a long term process that occurs only when there is a change in systematic and individual characteristics as follows: (1) 
educational vision that supports school culture [8]; (2) empowering ICT leaders to provide support and school leadership [1]; (3) professional, pedagogical and technological development for educational use and creation of teaching activities [22] and (4) changing the perception of the role of the classroom teacher to become both a colleague and a partner in the process and for the student to use ICT as a tool for learning, creating and sharing knowledge [15].

Fullan [9] defines three gradual dimensions of change in implementing teaching digital learning: (1) use of new hardware and software materials; (2) adoption of new teaching/learning practices and (3) changing beliefs and insights. It is a gradual and hierarchical process, with the first stage being the adaptation of technology for existing teaching- learning habits. At this stage technology will be used as a tool for a diversified illustration beyond the "board and chalk" and posters and written material. Later, when teachers have mastered this stage, their use of technology will increase, althoughtheir use of technology will still be technical in its nature. Rubric for characterizing and evaluating ICT teaching activities demonstrates the characteristics of socio-constructivist digital learning, referring to this level as an intermediate step on the way to optimize the use of technology for teaching and learning needs. According to this rubric: "The technological component might create interest and innovation, but with no fundamental change in the essence of the learning." [22].

The second stage of change is reflected in implementing pedagogical rationale with optimal digital learning. This is based on a learning community, on intelligent use of digital communication among learners and between the learners and the teacher, with cooperative information using a collaboration of online tools and a routine use of digital information accessible to any learner, anytime, anywhere [20]. At this stage the use of technology becomes valuable for teachers, since technology becomes essential in carrying out directed activities. According to the rubric, this is the stage where "Technology is essential for the activity. Students are referred to a variety of rich, current websites. They interact with the content by using Web 2.0 tools as active participants in online dialogue" [22].

Implementation of digital learning targeted at the student and conducted in an online learning environment is rich and up to date. The teacher must consider how to integrate the content taught with the new technological tools, based on the unique features and capabilities that characterize these tools. The teacher must plan how to use them, the degree of synchronization and the cooperation required to meet the objectives and requirements of learning [2]. This change can be accomplished through collaboration tools and construction of knowledge, provided by Web 2.0 technology. This enables the acquiring of knowledge through cooperation and communication, sharing textual, visual and auditory information with colleagues, and allowing students to add, edit, comment and respond to the information presented by other learners, whether jointly or individually. Acquisition of these teaching skills is part of the requirements demanded by the ICT program for teachers [16].

\subsection{Meaningful Digital Learning}

Learning becomes meaningful in a situation where learning is perceived as important, valuable and meaningful to the learner, in alignment with his world, the world of his concepts, his cognition and emotion. Therefore the presence of the learning process shapes the learner's life and reality, his personality, talents, and future development [16]. Digital learning is the innovative, pedagogical infrastructure of the 21st century, leading to meaningful learning. This includes applying the full range of pedagogical learning methods, using information and technology-based communication that enables empowered learning [19]. In this approach, the content and knowledge learned must be relevant to changing reality, while in addition to knowledge, students must acquire relevant skills required for optimal functioning in the 21st century. Such instruction, matched to student diversity, allows evaluation and feedback in real time, promotes the processes of teaching-learning assessment targeted at the individual and emphasize the development of learners capable of independent learning [24,25]. This learning occurs in a social context, removing barriers between the school and the outside world and allowing learners to integrate into society and to act in an ethical manner [19]. Digital learning is based on the accessibility of content units and existing digital teaching materials, along with intelligent use of information sources on the web, available to both teachers and students. Access to information from the network enables compliance with knowledge construction processes, research activities, exploration, sharing, and expanding. Such pedagogical activities require teachers to acquire knowledge that combines both the ability to use processes of teachinglearning-assessment quality and the ability to use technology. Koehler \& Mishra [13] call this innovative knowledge: "TPACK- Technological Pedagogical and Content Knowledge". This knowledge characterizes the teacher's ability to wisely integrate technology into teaching and to design learning activities that include technology based on up-to-date pedagogical principles and practicality $[22,25]$.

As far as we know, integrated evaluation research has not yet been carried out to examine the nature of the use of technological tools by teachers for teaching-learning purposes, nor has the relationship been explored between the use of these tools in changes caused by a new national, extensive ICT program. This research was created for that purpose.

\subsection{The Research Purpose}

The purpose of the research was to evaluate the level of influence the ICT program has on teachers' work.

\subsection{The Research Questions}

(1) What are the technological tools used by the teacher for teaching and learning and how are they used in teaching and learning?

(2) How do teachers perceive the changes they undergo following the entry of the ICT program into the school?

(3) Is there a connection between teachers who use various technological tools and their understanding of the ICT program's influence on their work? 


\section{The Research Method}

This is an integrated research method- both qualitative and quantitative. The qualitative portion examines the process of change, in regard to the reports of the teachers on the uses of technological tools and services in practice. The quantitative portion examines the results of the changed process following the entry of the ICT program to the school. The combination of quantitative and qualitative findings may contribute to a deeper and more significant understanding of the nature of change in the teacher's work through applying digital learning.

\subsection{Participants}

The research involved 1,035 teachers in primary schools who joined the national ICT program, "Adapting the Education System to Needs of the 21st Century" in 2011-2012. Samples of participants were taken in a random manner. Questionnaires were sent to all of the teachers in the ICT program, about 2,000 teachers in all.

Of the questionnaires received, 341 responses were from teachers in the first year of the program (32.9\%) and 694 responses were from teachers in the second year (67.1\%). Of all the teachers who responded to the questionnaire, 718 were from the Jewish sector (69.4\%) and 317 were from Arabic speaking teachers (Arab, Druze and Bedouin) (30.6\%). These teachers have an Mean of 15 years in teaching and education experience $(\mathrm{M}=15.12$, $\mathrm{SD}=9.35)$.

\subsection{The Research Tools}

The research consisted of a semi-closed questionnaire developed for the research, which contained three parts.

The first part examined the characteristics of the technological tools that were given as most useful by the teachers. The teachers were asked to report openly about technological tools and applications by the degree they are used in teaching and learning, with the level of efficiency as much higher in the first tool and lowest in the last tool. The maximum number of tools they were asked to report on were an overall of five with side notes of examples and descriptions of their uses.

The second part examined the level of impact the ICT program had on the teachers' teaching-learning. Teachers were asked to elaborate on the main change that occurred following their entry into the school's ICT program.

The third section examined the impact of the program on the teacher's work in an online environment. In this section, eleven items were developed, based on the principles of professional development which are presented in literature [17] and the national ICT targets [16]. Teachers were asked to present their views on the question: To what extent has the ICT program affected your work in an online environment with the various items as shown in Table 1? The Likert-type scaled questionnaire had five levels and ranged from "not at all" (1) to "very much" (5). The reliability of the questionnaire was $\alpha=92$. A free factor analysis (type Principal Components) with a Varimax rotation type did not cause distribution to factors. Therefore, an additional factor analysis has been made with two conditional factors, so that two Eigen values were received greater than 1 , resulting altogether in
$67.95 \%$ of the variance. Table 1 presents the details of the item factors.

Table 1. Results of Factor Analysis- Impact of the ICT program on teacher's work

\begin{tabular}{|l|l|}
\hline $\begin{array}{c}\text { Implementation of technological- } \\
\text { pedagogical innovations }\end{array}$ & \multicolumn{1}{|c|}{$\begin{array}{c}\text { Gaining technological- } \\
\text { pedagogical knowledge }\end{array}$} \\
\hline $\begin{array}{l}\text { q3. Working with students using } \\
\text { digital tools on the web to increase } \\
\text { creativity and learning }\end{array}$ & $\begin{array}{l}\text { q8. Development of personal } \\
\text { skills of searching, checking and } \\
\text { selecting information }\end{array}$ \\
\hline $\begin{array}{l}\text { q4. Development of class sites and } \\
\text { sub-content for teaching and } \\
\text { learning needs }\end{array}$ & $\begin{array}{l}\text { q9. Awareness of ethical } \\
\text { challenges as a result of conduct } \\
\text { on the web }\end{array}$ \\
\hline $\begin{array}{l}\text { q2. Combination of various media } \\
\text { in online teaching and learning } \\
\text { needs }\end{array}$ & $\begin{array}{l}\text { q7. Development of personal } \\
\text { skills for using information and } \\
\text { communication }\end{array}$ \\
\hline $\begin{array}{l}\text { q1. Choosing and matching of } \\
\text { online activities for teaching and } \\
\text { learning needs }\end{array}$ & $\begin{array}{l}\text { q5. Exploring digital content with } \\
\text { in sub-content areas }\end{array}$ \\
\hline $\begin{array}{l}\text { q6. Combination of digital content } \\
\text { in learning and teaching }\end{array}$ & q10. Exchanging information \\
with colleagues
\end{tabular}

At the end of the questionnaire the teachers answered demographic questions (teaching seniority, region, number of years in the program and sector).

\subsection{The Research Process}

In late 2012 a questionnaire was distributed among teachers in elementary schools from various regions in the country who were coming into the ICT program "Adaptation of the Education System Needs of the 21st Century", and were working in the first or second year of the program. Teachers were asked to complete the questionnaire online. Completion of the questionnaire took about 30 minutes.

\subsection{Data Analysis}

In the first part $84 \%$ of the teachers described uses of technological tools. $16 \%$ of the teachers did not respond. Some of them may have misunderstood or did not read the question carefully, resulting in some of the answers being vague and general with descriptions such as "internet", "projector", "computer", without reference to specific tools. It was therefore decided that this data would not be incorporated into the results. However, reports that included a detailed explanation regarding the way of implementing the tool without specifying the name of the tool were interpreted by the investigators as to the teacher's intentions.

The second part of the questionnaire was answered by $97 \%$ of the teachers and the third part was answered by $100 \%$ of the teachers. In the first and second parts, analysis was conducted based on the "grounded theory in the field" approach [5]. Each part had a separate content analysis performed. The process of building and phrasing categories included three main steps: (1) open coding: repetitive themes, (2) axial coding: remapping of the findings along the axis of each category, according to the same themes and (3) selective coding: broadening of the categories and themes. The goal was to reach the "core categories" and through them explain the different uses of teachers' technology tools and perception of change following the ICT program. The third part was statistically analyzed using the SPSS. 


\section{Findings}

\subsection{The Technology Tools Used by the Teacher for Application of Digital Teaching-Learning}

With reference to the initial research question "What are the technological tools used by the teacher for teaching-learning, and how are they used in teachinglearning?", teachers were asked to report on up to five technology tools, ranked according to their use in teaching and learning and to provide examples of how they apply them. The mean each teacher reported on two tools. A content analysis was conducted on the statements given by the teachers. These statements were grouped into nine categories presented.

\subsection{Categories of the Tools the Classroom Teacher Uses}

1) Tools of visual demonstrations- Photo albums, watching YouTube and other videos and editing their information, Google Earth, simulations, concept organizers (like Popplet), illustration via visual embodiment. Two tools that have especially been emphasized were YouTube and Google Earth stock videos. Teacher quotes (examples): "... I often use visuals ... videos serve as an important instrument for me, for the purpose of presenting a topic or theme summary ..." "the Google Earth tool - is used in geography lessons to illustrate phenomena and characteristics of places ... and in Bible lessons - to illustrate the places mentioned in the Bible ..."

2) Digital content- Watching, using and displaying of online class materials such as professionally produced content, by various means, including digital books. Teacher quotes (examples): "Screening of the digital book and presenting the concepts and pictures in the book in front of all the students. Facilitating a discussion about the ideas the book raises." "... I present the learning material to the students (on the Educational Technology Center website)."

3) Production tools- Lyricist, presentations, spreadsheet, video producing and editing, etc. ("Office" tools). Teacher quotes (examples): "... After I teach the students about the tool (Smart-Art) I ask them to present information taught through an appropriate chart...", "With the help of Publisher, I prepare posters and postcards with the students."

4) Collaborative tools- Exposing the students to learning through blogs, forums, shared documents, social networking, surveys, etc. The most common tools were Google Docs, social networks, and forums. Teacher quotes (examples): "In the forum we give out feedback of the students' results following the presentation - the lectures that children give in class..." "First I made a digital form. Then, during class, the students' explanations were gathered following a mathematical question regarding the need to impart the skill of writing mathematical explanations..."

5) Pedagogical management tools- Managing learning (attendance, grades, behavior) through a designated pedagogical network tool. Teacher quotes (examples): Management and registration - attendance, equipment, homework, behavior, participation, and more ..."
6) Media tools- E-mail, forum, chat, texting, Skype, video conferences. The main tools were e-mail and chat. Teacher quotes (examples): "I often carry out work through the forum, which allows 'Ping Pong' - sending papers between the teacher and student for improvement and notes..."

7) Information retrieval tools- Retrieval of web information, use of online databases designated for learning topics, and general buffers such as encyclopedias, Wikipedia, Wikitionary, etc. The most frequently used tool was Google, a search engine. Teacher quotes (examples): "... Following the annual lesson on leaders, children wrote questions and found answers using the references presented on the school portal..."

8) Organizing information on Cloud tools- Dropbox, Google Drive, Microsoft SkyDrive. Teacher quotes (examples): "... Students in the class are creating joint presentations together..."

9) Game tools- Various games and comics (like ToonDoo).Teacher quotes (examples): "... During language class I created a comic illustrating a dialogue between characters..."

Content analysis shows that technological tools used by teachers for teaching are diverse digital learning. Categories of "Organizing information on Cloud" tools and "Game tools" had a comparably low level of use; therefore these categories were omitted from further analysis. Figure 1 shows the frequency of use of the teachers' most preferred technology tools.

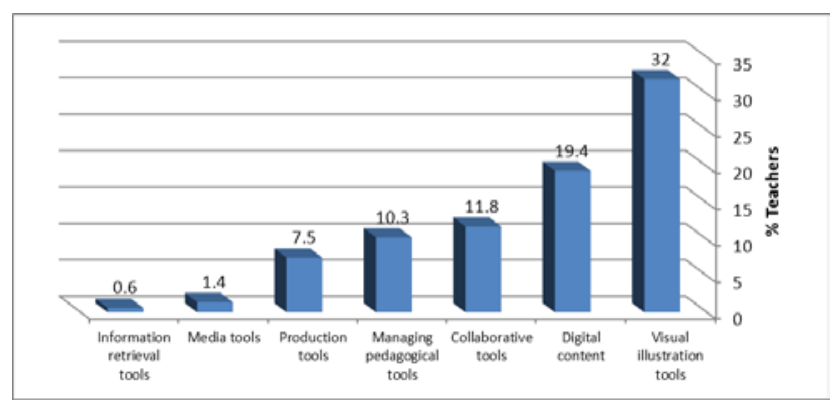

Figure 1. Prevalence of the technology tool's use with the highest priority $(\mathrm{N}=1035)$

Figure 1 shows that the use of visualizations is most often followed by the use of digital content. An interesting finding was obtained in the category of the most preferred tool. In this category, it was found that about a third of the teachers prefer the use of visualization tools, about a fifth of the teachers prefer the use of digital content and only about a tenth of the teachers reported that the collaborative tools are their most preferred tools.

\subsection{The Perception of Change Following the ICT Program}

With regard to the second research question "How do teachers perceive the changes they undergo following the entry of the ICT program into the school?" Content analysis was conducted and the reports were coded, resulting in twelve categories. Usually a teacher would indicate which change is the most significant one for them, within at least two categories. The most common category is 'illustrative'. It was discovered that $40.8 \%$ of teachers report that the main change that occurred following their 
national ICT program was the use of technology for illustrative purposes. Another common category is 'motivation for learning'. It was found that $33.7 \%$ of teachers report that they use technology to motivate student learning. According to them, the integration of technology in teaching and learning creates a stimulus and greater level of interest. Teachers reported that the lessons are becoming more interactive, interesting and challenging, for example: "...it is easier to illustrate, to explain. Children can learn visually and track what has been done in the class... teaching is dynamic, the visualized illustrations stimulate the students to gain interest in many subjects". Categories that emerged and were noted as used rarely were 'improving the learning environment', 'thought development', 'sharing' and 'communications'. It was found that between $2.4 \%$ and $4.6 \%$ of teachers reported changes in these areas. This indicates that few teachers reported a change their work following the national ICT program with regard to improving the learning environment in the classroom, promoting development of higher-order thinking, cooperative learning development and creating a more continuous communication between all those involved. Figure 2 shows the frequency of the teachers' change characteristics following the entry of the ICT program in school.

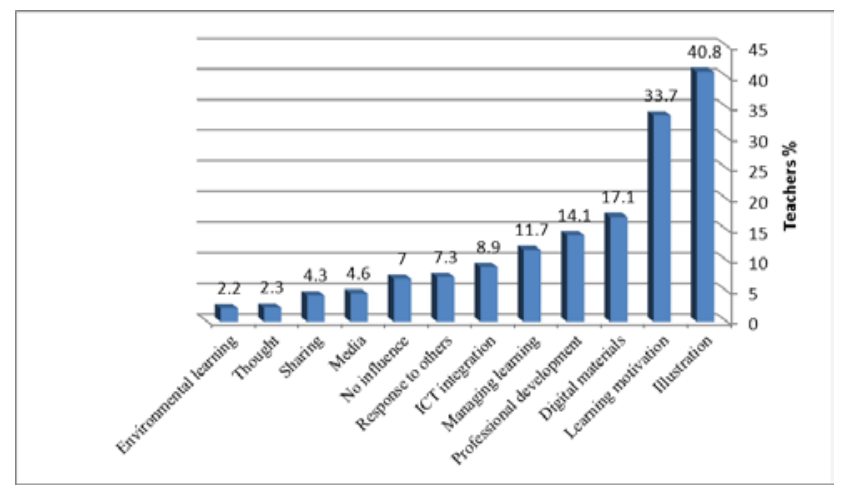

Figure 2. Prevalence and characteristics of transformation of teachers following the entry of the school ICT program $(\mathrm{N}=1008)$

\subsection{Impact of the Program on Teachers' Work in an Online Environment}

With regard to the third research question concerning the relationship between the use of types of technology tools and the understanding of the influence the program has on their work, the initial matter to be tested was between the two variables defined as expressing the concept of the ICT program's effect: (1) implementation of technological-pedagogical innovations and (2) acquisition of technological-pedagogical knowledge. The Pearson correlation was made between the two, and a positive, high and significant correlation was found $(\mathrm{r}=$ $0.77, \mathrm{p}<0.01$ ). This signifies that as much as the program contributes to the implementation of technologicalpedagogical innovation in the classroom, the more it contributes to acquiring technological-pedagogical knowledge, and vice versa. Figure 3 shows the Mean of each variable (Comment: Details q1-q10 in Table 1).

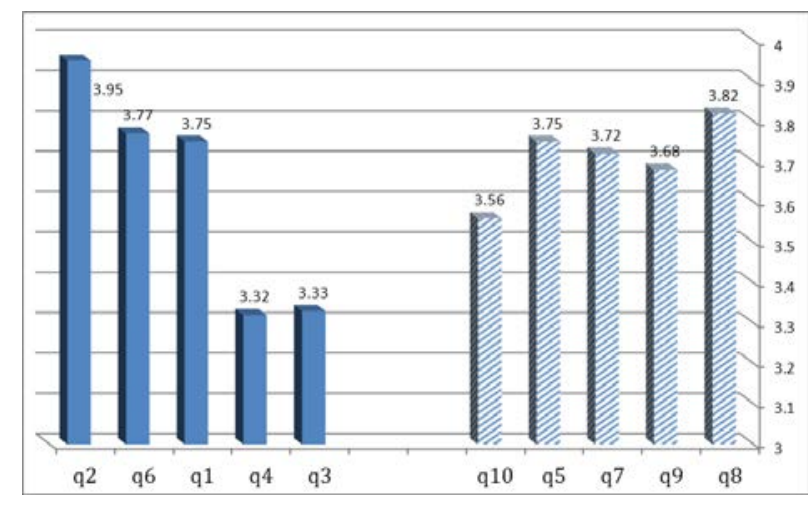

Figure 3. Mean of the items of the ICT program's effect variables $(\mathrm{N}=1035)$

In order to determine whether differences exist between teachers who use the tools and the various technological tools with the highest priority (collaborative tools and communication tools were joined and called collaboration and communication tools), on the level of the ICT program's influence on their work (application of technological-pedagogical innovation and acquiring technological-pedagogical knowledge) a One Way MANOVA analysis was conducted. The analysis found no significant difference between teachers who use different technological tools, $\mathrm{F}(14,2052)=5.00 ; \mathrm{p}<0.001, \eta^{2}=.033$. Further on, One Way ANOVA was conducted, which were designed to test the source of significance between teachers who use different technological tools. Results of the analysis are presented in Table 2.

Table 2. Means, standard deviations and $F$ values of the components of the impact of ICT program ( $N=1025)$

\begin{tabular}{|c|c|c|c|c|c|c|c|c|c|c|c|c|c|c|}
\hline & \multicolumn{2}{|c|}{$\begin{array}{c}\text { Use of } \\
\text { information } \\
\text { retrieval }(\mathrm{N}= \\
110)\end{array}$} & \multicolumn{2}{|c|}{$\begin{array}{l}\text { Use of visual } \\
\text { illustrations }\end{array}$} & \multicolumn{2}{|c|}{$\begin{array}{c}\text { Use of } \\
\text { collaboration and } \\
\text { communication } \\
\text { tools }(\mathrm{N}=136)\end{array}$} & \multicolumn{2}{|c|}{$\begin{array}{l}\text { Use of } \\
\text { producing tools } \\
(\mathrm{N}=78)\end{array}$} & \multicolumn{2}{|c|}{$\begin{array}{l}\text { Use of digital } \\
\text { content } \\
(\mathrm{N}=201)\end{array}$} & \multicolumn{2}{|c|}{$\begin{array}{c}\text { No use } \\
(\mathrm{N}=168)\end{array}$} & \multirow[t]{2}{*}{$\begin{array}{c}F \\
(5-1019)\end{array}$} & \multirow[t]{2}{*}{$\eta^{2}$} \\
\hline & $\mathrm{M}$ & SD & $\mathrm{M}$ & SD & M & SD & $M$ & SD & $M$ & SD & $\mathrm{M}$ & SD & & \\
\hline $\begin{array}{c}\text { application of } \\
\text { Technological- } \\
\text { Pedagogical } \\
\text { innovations }\end{array}$ & 3.59 & 0.85 & 3.67 & 0.72 & 3.99 & 0.77 & 3.53 & 0.90 & 3.69 & 0.77 & 3.33 & 1.00 & $0.38^{* * *}$ & 0.048 \\
\hline $\begin{array}{c}\text { acquiring } \\
\text { Technological- } \\
\text { Pedagogical } \\
\text { Knowledge }\end{array}$ & 3.66 & 0.79 & 3.78 & 0.76 & 4.04 & 0.78 & 3.68 & 0.83 & 3.72 & 0.78 & 3.36 & 0.91 & $1.32^{* * *}$ & 0.053 \\
\hline
\end{tabular}

$* * * \mathrm{p}<.001$

Table 2 shows statistically significant differences, which were found in a mean application of the technological-pedagogical innovation and mean acquisition of technological-pedagogical knowledge between teachers who use various technological tools.
Further on, analyses were conducted of comparison between pairs according to Scheffe, in order to locate the source of the differences between the teachers. These analysis results clearly showed that teachers who use collaboration and communication tools in their work 
report that the ICT program affects the implementation of the technological-pedagogical innovation in the classroom to a greater extent than the teachers who use production tools, visual illustrations, information retrieval and who are not using the tools at all. However, no significant differences were found between teachers who use collaboration and communication tools and those who use digital content.

In addition, the analysis results clearly demonstrated that teachers who use collaboration and communication tools in their work, report that the ICT program affects the acquisition of technological-pedagogical knowledge to a greater extent than teachers who use digital content, information retrieval and who do not use it at all.

Furthermore, the Scheffe analysis results clearly showed that teachers who use digital content and visual illustrations report that the ICT program affects the implementation of the technological-pedagogical innovation to a greater extent than teachers who do not use technological tools (Figure 4).

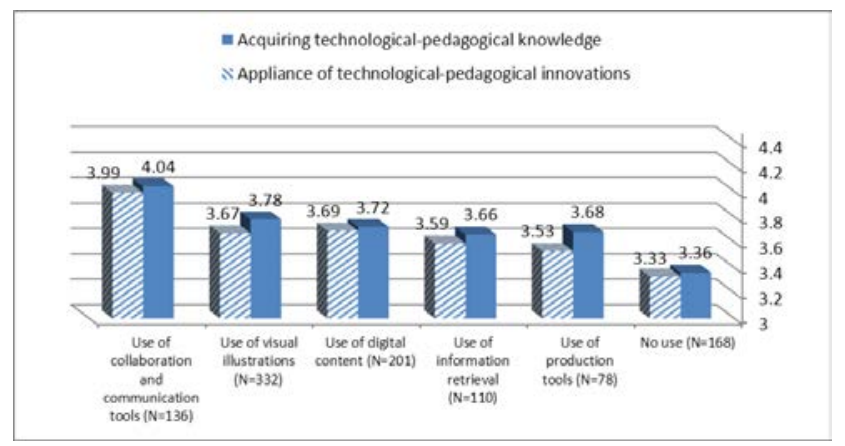

Figure 4. Differences between the types of technological tools $(\mathrm{N}=1025)$

\section{Discussion and Conclusions}

Since 2010 the Israeli educational system has implemented an ICT program "Adaptation of the Educational System to the 21st Century" in order to achieve pedagogical change which will promote significant learning and acquisition of 21st century skills. In this research multiple indicators of combination digital teaching-learning were examined. The synergy from the merged results of these indicators is clearly demonstrated through changes in the schools. At first, the technology tools were examined, as they were used by teachers for the purpose of teaching-learning, followed by an examination of their perceptions regarding the changes they underwent following the entry of the ICT program into the school system. The last section examined attitudes about the impact of the ICT program on their work in the context of implementation of technological-pedagogical innovation and acquisition of technological-pedagogical knowledge.

Research findings show that following the entry of the ICT program into the school, significant change occurred in teachers' perceptions regarding understanding the additional value of integrating technology into teaching. Most teachers indicate that ICT helps them illustrate complex content and creates motivation for learning among students. Some refer to the professional empowerment they experience as teachers following the acquisition of technology skills, allows them to open up to a world of teaching and learning beyond what they knew previously. For example, teachers wrote that "the combination of internet study materials varies learning methods and helps the students understand the lessons. This learning is experiential. It allows exposure to new and extensive information, (...) shared teacher-student learning while allowing the use of educational materials from the internet... (...) The main change is the experience that was created for me and the students. ICT encourages them to know and search for themselves and that is why the lesson becomes more interesting for the students and for me $(. . .)^{\prime \prime}$.

The research reveals the technological tools used by teachers in their work and the additional value they attribute to the use of these tools for teaching. Tools which were found as particularly prominent were the visualization illustration and digital content tools. Teachers reported that "presentation of the materials in different ways and in more ways than of those in the past, i.e., a combination of content, movies, presentations, elearning activities (...) I have added another tool to my teaching, which allows me to illustrate abstract concepts in various ways that until now were difficult to illustrate. Pupils can continue to use illustrations at home through the link I attach and use them in their homework preparation..(...)". These findings reinforce previous studies which have found that initial application of the digital teaching-learning is basic and integrated into current learning activity [22], and more importantly, the way it is integrated preserves existing traditional pedagogy [10]. That is, teachers' perceptions regarding the implementation of digital teaching-learning focus on technology as a means to diversify existing teaching methods [14] as well in terms of access to information and educational materials on the web [7] and less as promoters of technological-pedagogical innovation.

The use of production and collaboration tools in this research was of mean prevalence, following the use of visual illustration and digital content tools, which many teachers use and consider being most meaningful in terms of integrating technology into teaching. The teachers use the collaboration tools as tools which encourage the creation of shared information and its presentation to groups or individuals. Sometimes collaboration occurs between the teacher and student, but in most cases the work is shared among all students in the class. Such tasks enable online sharing in an efficient and comfortable way between students from other schools, as was reported by two teachers: "Online work is done in groups so that each child has a role and each feels equal, as they have contributed their part according to their skills... (..) Collaborative learning is enabled thanks to the variety of tools that we have acquired. They allow us to use numerous new tools for presenting information and creating new knowledge for the teacher and students $(\ldots) "$. More can be learned from the teachers' reports that the production and collaboration tools allow them to promote open and creative work more than just using visualization tools and digital content. These open, collaborative tools allow the teacher to create their own teaching activities according to their pedagogical needs and to enrich and diversify their work. The student is given the opportunity to learn actively, to create information and to share it with his colleagues and teachers. For example, teachers reported that: "Students are more active during lessons 
and in the computer tasks they receive for homework (...) I encourage students to use various network applications that help create new information (...) I have created my own presentation showing works of artists. The students produce presentations inspired by what I have presented (...)".

Teachers who use collaboration and communication tools in their classroom are considerably advanced in their expertise of current technological-pedagogical thinking in the classroom when compared to teachers who do not use these tools. We believe this finding is the most significant indicator in this research. According to this, promoting significant digital teaching and learning is possible only when teachers encourage learners to act in a collaborative manner and to learn while interacting and socializing $[3,4]$. That is, cooperative learning is the key to quality learning in the digital age [21]. Therefore, to enable teachers to adopt such approaches, it is desirable to adapt the curriculum and methods of assessment in a way which promotes collaborative learning, encourages teachers to use these tools and enables the creation of meaningful social relationships, which assist the students in constructing new personal knowledge [23].

From the research, it is indicated that the effect of the program on the implementation of digital teachinglearning is already evident on the national level. That is, the educational system is presently at a point where most of the teachers are involved in the change process. According to Rogers model "Diffusion of Innovation" [18] the critical mass of teachers, called the early and late majority, is already involved in implementing a change. Only $16 \%$ of teachers are not yet using technological tools in their teaching. We believe that this is the time to promote the level of the implementation process and to encourage the necessary pedagogical attitude. The education system must continue to move beyond the first step of the implementation process into phase two. The system must continue to support the empowerment of teachers' professional development, support the classroom application process and set clear requirements regarding how the application is required and its quality in practice. Such clear requirements for such a trend may promote the expansion of its widespread change in additional groups of teachers, including new teachers entering the system [22]. The recommended pedagogical sphere is based on the assumption that teachers' professional knowledge is one which combines the best pedagogy, technological information and knowledge in the field of discipline $[13,15]$.

Therefore, as a general rule, it is safe to say that teachers are not yet in the advanced second stage of using collaborative tools and structuring of knowledge tools provided by Web 2.0 technology, even though the schools where they work are in the first and second year of participation in the ICT program. Hence, one cannot expect to change the systemic nature of this directive within two years of program operation. However, it can be assumed that with time and with the acquisition of selfconfidence among teachers about their ability to use the tools on the one hand, and their understanding of the added pedagogical value of using these tools on the other, it seems many examples of digital teaching-learning are optimized. For example, teachers reported that "For a large part of the lessons, I became a guiding teacher and the students became active in the learning process (...).
The collaborative tools of Google Docs have significantly improved my instructions. The pupils are more dynamic in lessons; share their products with the class... less frontal teaching. The teachers in the team are partners in planning their teaching activities (...)". These examples illustrate the essence of meaningful learning, which is relevant to the world of students, encourages activity and creativity, promotes cooperation and dialogue between peers, enables learning outside the classroom, considers diversity and encourages inquisitive learning $[9,10]$.

In summary, in examination of the extent of change combined in digital teaching-learning in schools through a comprehensive program that provides built-in equipment and training for teachers, a large-scale change occurred in teachers' classroom activity and in their perceptions of pedagogical essence, which is necessary for the integration of technology into teaching. But in that twoyear time period, this remains only the initial change. These findings indicate that most teachers use technology as an addition to existing teaching-learning and do not implement a profound change that leads from traditional teaching to the digital teaching-learning application that enables meaningful learning. We assume that if the system continues to support the training of teachers in the next few years and succeeds in charting a pedagogicalappropriate way that is also consistent and systematic, a significant change could be expected in the nature of teachers' work in relation to the characteristics of digital learning-teaching.

\section{References}

[1] Avidov-Ungar O., Shamir-Inbal, T. (2013). Empowerment Patterns of Leaders in ICT and School Strengths following the Implementation of National ICT Reform. Journal of Information Technology Education: Research, 12. from:

http://www.jite.org/documents/Vol12/JITEv12ResearchP141158Avidov1228.pdf.

[2] Bower, M., Hedberg, J. G., \& Kuswara, A. (2010). A framework for Web 2 learning design. Educational Media International, 47 (3), 177-198.

[3] Capper, J. (2003). Complexities and Challenges of Integrating Technology Into the Curriculum. TechKnowLogia, 5 (1).

[4] Cole, M. \& Wertsch, J. (1996). Beyond the Individual-Social Antimony in Discussions of Piaget and Vygotsky Human Development, 39, 250-256.

[5] Corbin, J., \& Strauss, A. (1990). Grounded theory research: Procedures, canons, and evaluative criteria. Qualitative Sociology, 13(1), 3-21.

[6] Cuban, L. (2001). Oversold \& underused: Computers in the classroom: Harvard university press Cambridge, Massachusetts London, England.

[7] Darling-Hammond, L., \& Youngs, P. (2002). Defining "highly qualified teachers": What does "scientifically-based research" actually tell us? Educational Researcher, 31 (9), 13-25.

[8] Ertmer, P. A., \& Ottenbreit-Leftwich, A. T. (2010). Teacher technology change: How knowledge, confidence, beliefs, and culture intersect. Journal of Research on Technology in Education, 42(3), 255-284.

[9] Fullan, M. (2001). The new meaning of educational change (3rd ed.) New York and London: RoutledgeFalmer.

[10] Fullan, M. (2011). The moral imperative realized. Thousand Oaks, CA.: Corwin Press; Toronto: Ontario Principals Council.

[11] Hadjithoma-Garstka, C. (2011). The role of the principal's leadership style in the implementation of ICT policy. British Journal of Educational Technology, 42(2), 311-326.

[12] Ilomaki, L. (2008). The effects of ICT on school: Teachers' and students' perspectives. University of Torku, Finland. https://oa.doria.fi/bitstream/handle/10024/42311/B314.pdf?sequen $\mathrm{ce}=3$. 
[13] Koehler, M., \& Mishra, P. (2008). Introducing TPCK. In AACTE Committee on Innovation and Technology (Ed.), Handbook of technological pedagogical content knowledge (TPCK) (pp.3-30). New York: Routledge.

[14] Kozma, R. B. (2010). ICT Policies and Educational Transformation. A UNESCO publication.

[15] Magen-Nagar, N., \& Peled, B. (2013). Characteristics of Israeli School Teachers in Computer-based Learning Environments. Journal of Educators Online. http://www.thejeo.com/Archives/Volume10Number1/MagenNager.pdf.

[16] Ministry of Education, Israel (2013). The National ProgramAdapting the Education System to the 21st Century- vision and rationale. Retrieved on September 1, 2013 from http://cms.education.gov.il/EducationCMS/Units/MadaTech/ICTI nEducation/Odot/ [Hebrew].

[17] Pellegrino, J. W. \& Hilton M. L. (Eds.). (2012). Education for Life and Work: Developing Transferable Knowledge and Skills in the 21st Century. Committee 011 Defining Deeper Learning and 21' Centuiy Skills. National Research Council of the National Academies.

[18] Rogers, E. M. (2003). Diffusion of Innovations. (5th ed.) New York: Free Press.
[19] Rotem, A. (2013). Digital Learning- Rationale and recommendations for implementation. Retrieved on September 1, 2013 from: http://avrumrotem.com [Hebrew]

[20] Scardamalia, M., \& Bereiter, C. (1999). Schools as knowledgebuilding organizations. In D. Keating \& C. Hertzman (Eds.), Today's children, tomorrow's society: The developmental Health and Wealth of Nations (pp.274-289). New York, NY: Guilford.

[21] Shamir-Inbal, T., \& Kali, Y. (2009). Teachers as designers of online activities: The role of socio-constructivist pedagogies in sustaining implementation. Design Principles \& Practices: An International Journal, 3 (1), 89-100.

[22] Shamir-Inbal, T., Dayan, J., \& Kali, Y. (2009). Assimilating Online Technologies into School Culture. Interdisciplinary Journal of E-Learning and Learning Objects. special issue.

[23] Siemens, G. (2008). Learning and knowing in networks: Changing roles for educators and designers. Paper 105: University of Georgia IT, from: http://it.coe.uga.edu/itforum/Paper105/Siemens.pdf.

[24] Voogt, J. (2012a). Are teachers ready to teach in the knowledge society? Considerations based on empirical findings. Jahrbuch Medienpädagogik, 9, 17-28.

[25] Voogt, J. (2012b). ICTs for Curriculum Change, Iite Policy Brief. Published by the UNESCO Insti tute for Informati on Technologies in Educati, Moscow. http://iite.unesco.org/pics/publications/en/files/3214717.pdf. 